\title{
Tianwen-1 Mars entry vehicle trajectory and atmosphere reconstruction preliminary analysis
}

\author{
Haogong Wei ${ }^{1}(\otimes)$, Wei Rao ${ }^{1}$, Guangqiang Chen $^{2}$, Guidong Wang ${ }^{2}$, Xin Zou ${ }^{1}$, Qi Li $^{1}$, \\ and Yanqi $\mathrm{Hu}^{1}$
}

1. Beijing Institute of Spacecraft System Engineering, Beijing 100094, China

2. China Academy of Aerospace Aerodynamics, Beijing 100074, China

\begin{abstract}
The Tianwen-1 Mars entry vehicle successfully landed on the surface of Mars in southern Utopia Planitia on May 15, 2021, at 7:18 (UTC+8). To acquire valuable Martian flight data, a scientific instrumentation package consisting of a flush air data system and a multilayer temperature-sensing system was installed aboard the entry vehicle. A combined approach was applied in the entry, descent, and landing trajectory reconstruction using all available data obtained by the inertial measurement unit and the flush air data system. An aerodynamic database covering the entire flight regime was generated using computational fluid dynamics methods to assist in the reconstruction process. A preliminary analysis of the trajectory reconstruction result, along with the atmosphere reconstruction and aerodynamic performance, was conducted. The results show that the trajectory agrees closely with the nominal trajectory and the wind-relative attitude. Suspected wind occurred at the end of the trajectory.

KEYWORDS

Tianwen-1

flush air data system (FADS)

trajectory reconstruction

Martian atmosphere

aerodynamics

Research Article

Received: 17 September 2021

Accepted: 18 October 2021

(C) The Author(s) 2022
\end{abstract}

\section{Introduction}

The Tianwen-1 Mars entry vehicle successfully landed on the surface of Mars in the southern Utopia Planitia on May 15, 2021, at 7:18 (UTC+8). The Tianwen-1 Mars exploration mission consists of three major parts: orbiting, landing, and roving. The Tianwen- 1 spacecraft, launched aboard CZ-5B from Wenchang on July 23, 2020, was injected into the Mars orbit in February 2021, and it stayed in the orbit for two and a half months. Sand storm observations over the landing site and general optical surveillance tasks were conducted during this period.

The entry, descent, and landing (EDL) sequence of Tianwen-1 is shown in Fig. 1. The entry interface was $125 \mathrm{~km}$ with a velocity of $4.7 \mathrm{~km} / \mathrm{s}$. The entry vehicle went through "nine minutes of terror" using a trim angle of attack at approximately $-10^{\circ}$ to gain lift for banking maneuvers in most of the flight, and it reached peak heating at an altitude of approximately $60 \mathrm{~km}$. A trim tab was deployed at 2.8 Mach to trim the angle of attack toward 0 . The parachute deployment was triggered at
1.8 Mach, followed by parachute descent, heat shield jettison, and radar activation. The powered descent segment was initiated after backshell separation, where potential obstacle avoidance occurred. Finally, the vehicle touched down on Martian soil $510 \mathrm{~s}$ after entry.

A flush air data system (FADS) and an in-layer temperature-sensing system were included in the scientific instrumentation package aboard the Tianwen-1 entry vehicle to overcome the absence of in situ atmospheric parameter measurements and to estimate the aerothermal environment during the flight. Unlike trajectory and atmosphere reconstruction on the Earth, the reconstruction of Martian flights encounters a lack of in situ atmospheric parameter measurement approaches, such as sounding rockets. The application of FADS makes accurate dynamic pressure estimation possible, thereby making atmospheric reconstruction feasible. Moreover, wind-relative attitudes, such as the angle of attack and sideslip, are available because the wind component is separated from the planet-relative attitude. 


$\begin{array}{llll}\text { Nomenclature } & & & \\ a_{x}, a_{y}, a_{z} & \text { acceleration }\left(\mathrm{m} / \mathrm{s}^{2}\right) & M_{\infty} & \text { free stream Mach number } \\ \text { ADB } & \text { aerodynamic database } & p_{\mathrm{t}} & \text { total pressure (Pa) } \\ \text { B } & \text { angle of sideslip }\left(^{\circ}\right) & p_{\infty} & \text { static pressure (Pa) } \\ \text { CFD } & \text { computational fluid dynamics } & \bar{q}_{\infty} & \text { dynamic pressure (Pa) } \\ \text { EDL } & \text { entry, descent, and landing } & \text { RCS } & \text { reaction control system } \\ \text { FADS } & \text { flush air data system } & \text { UTC } & \text { universal time coordinated } \\ \text { IMU } & \text { inertial measurement unit } & \alpha, \text { AoA } & \text { angle of attack }\left({ }^{\circ}\right) \\ M & \text { mass }(\mathrm{kg}) & \rho_{\infty} & \text { atmospheric density }\left(\mathrm{kg} / \mathrm{m}^{3}\right)\end{array}$

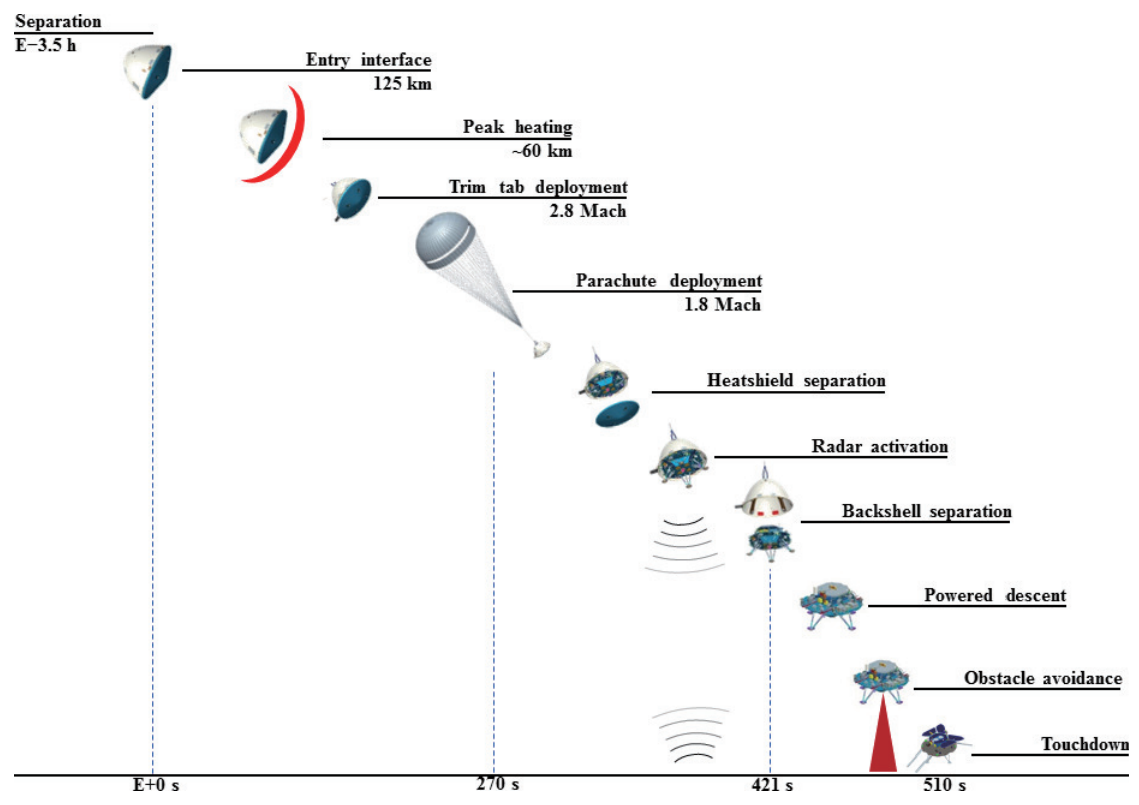

Fig. 1 Tianwen-1 entry, descent, and landing.

Research on FADS was first initiated by the US National Aeronautics and Space Administration (NASA) in the 1960s to gather air data in the hypersonic flight regime where the classical Pitot static probe failed to survive. The first application was the X-15 experimental airplane with a limited outcome 0 . The Shuttle Entry Air Data System (SEADS) was a complete success that invented the filter algorithm [2-4]. In the development of the X-33 program, various simplifications and progress on the FADS were made to improve the overall performance [5]. This design experience on the blunt forebody was implemented thereafter on a variety of hypersonic and supersonic flight vehicles [6-8].

Trajectory reconstructions of Mars entry missions prior to the Mars Science Laboratory (MSL) relied solely on inertial measurement unit (IMU) data, which are not capable of separating wind-relative parameters, such as the true angle of attack and sideslip [9-15].
MSL was the first mission to deliver an in-depth understanding of the Martian entry environment. MSL carried an instrumentation package, known as the MSL Entry, Descent, and Landing Instrumentation (MEDLI), comprising two major subsystems: the Mars Entry Atmospheric Data System (MEADS) and the MEDLI Integrated Sensor Plugs (MISP) [16-25]. Following MEDLI, the MEDLI2 sensor suite was developed to expand the set of measurements of the MEDLI suite [26, 27].

The objectives of the Tianwen-1 in-flight scientific measurements are as follows:

(1) Estimating the entry trajectory and aerothermal environment using flight data to support atmospheric reconstruction and design evaluation.

(2) Reconstructing the in situ Martian atmosphere that the entry vehicle experienced during flight.

(3) Evaluating the aerodynamic design, thermal 
protection design, and control system performance of Tianwen-1.

This study focused on trajectory and atmosphere reconstruction using IMU and FADS data. Aerothermal environment reconstruction is beyond the scope of this study. An overview of the instrumentation, the reconstruction techniques, and a discussion of the results are presented. The lessons learned should help improve planetary EDL performance in the future.

\section{Instrumentation}

\subsection{Inertial measurement unit}

The on-board IMU stores accelerations and angular rates at $0.25-2 \mathrm{~Hz}$. The sparseness of the data makes aerodynamic moment reconstruction difficult because the duration of a single control impulse of the reaction control system (RCS) is much shorter than the sampling time. It has little effect on the trajectory and aerodynamic force reconstructions, however, because RCS thrusters are activated only in pairs.

\subsection{Flush Air Data System}

The Tianwen-1 FADS contains seven pressure sensors connected to orifices on the heat shield. The locations of these orifices, denoted as P1, P2, .., P7 in Fig. 2, were intentionally selected for better performance while avoiding structural reinforcements. Specifically, P1 is at the center of the heatshield, P3 is the stagnation point throughout most of the flight until the trim tab deployment, and P2 and P3 are symmetrical with respect to $\mathrm{P} 1 . \mathrm{P} 4, \mathrm{P} 5, \mathrm{P} 6$, and $\mathrm{P} 7$ are arranged in a cross shape from $45^{\circ}$ to $315^{\circ}$ with an equal radial distance to $\mathrm{P} 1$.

The Martian flight data collection was initiated $15 \mathrm{~s}$ prior to entry and was terminated by the heat shield jettison. The pressure data were gathered at a constant sampling rate of $10 \mathrm{~Hz}$. Individual calibrations were performed for all seven pressure sensors before launch. The operating temperature ranging from -40 to +70 ${ }^{\circ} \mathrm{C}$ was divided into seven segments, each with specific fitting equations, to obtain high precision. Principal errors included transducer error, pipe pressure loss, and storage error, resulting in a maximum total error of no more than $\pm 7 \mathrm{~Pa}$. As a result, only data below $80 \mathrm{~km}$ were available.

The corrected in-flight pressure data are shown in Fig. 3, where P1, P2, - ., P7 represent the pressure data collected from the orifices corresponding to Fig. 2. No jumps or outliers were found, indicating high-quality measurements. Based on the orifice arrangement and pressure data (especially $\mathrm{P} 4$ through $\mathrm{P} 7$ ), an intuitive inference is that there was no significant sideslip in most of the flight.

\section{Methods}

\subsection{Pressure model}

The FADS is assisted by an aerodynamic database (ADB) covering the entire flight regime generated by computational fluid dynamics (CFD) methods. The computed points are shown in Fig. 4, where the blue crosses are the computed points of the aerodynamic database, and the red line shows the nominal trajectory. The primary objective of building such an ADB is to
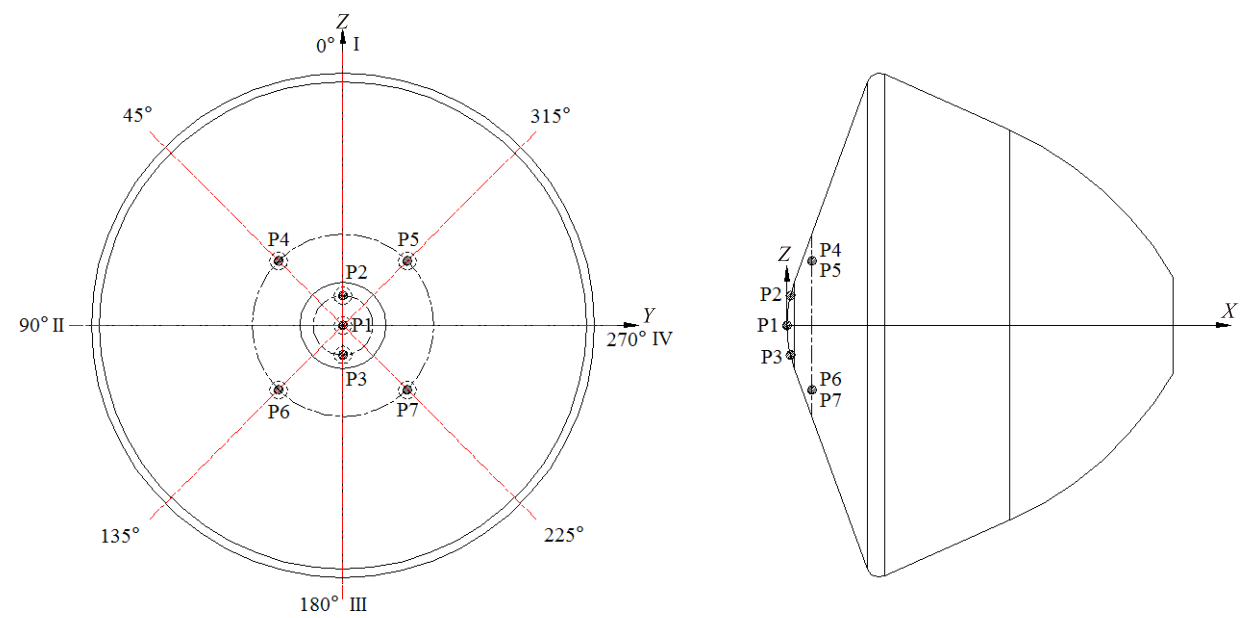

Fig. 2 Pressure orifice locations. 
facilitate trajectory reconstruction with a table lookup model by acquiring the pressure distribution of the entry vehicle at different wind-relative attitudes.

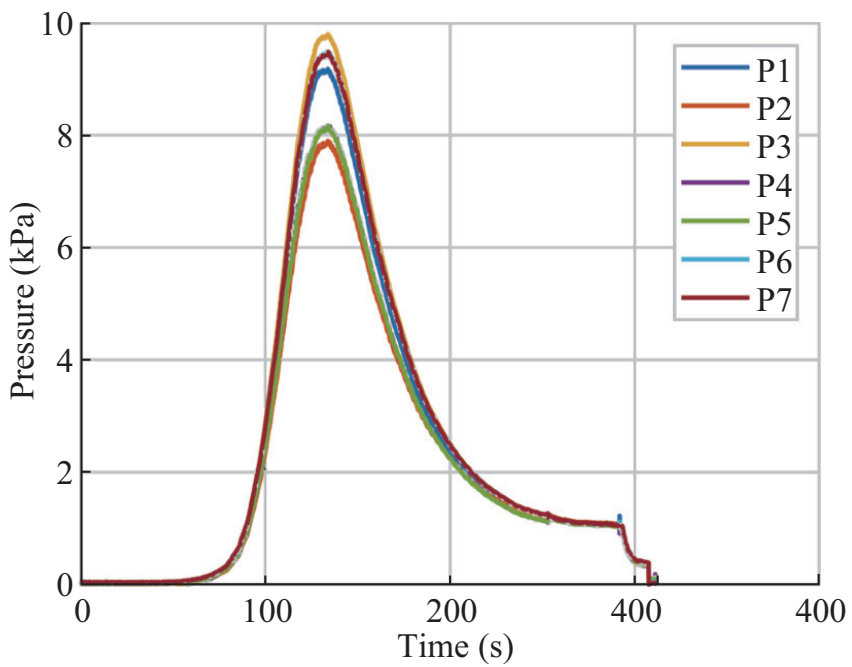

Fig. 3 In-flight pressure data.

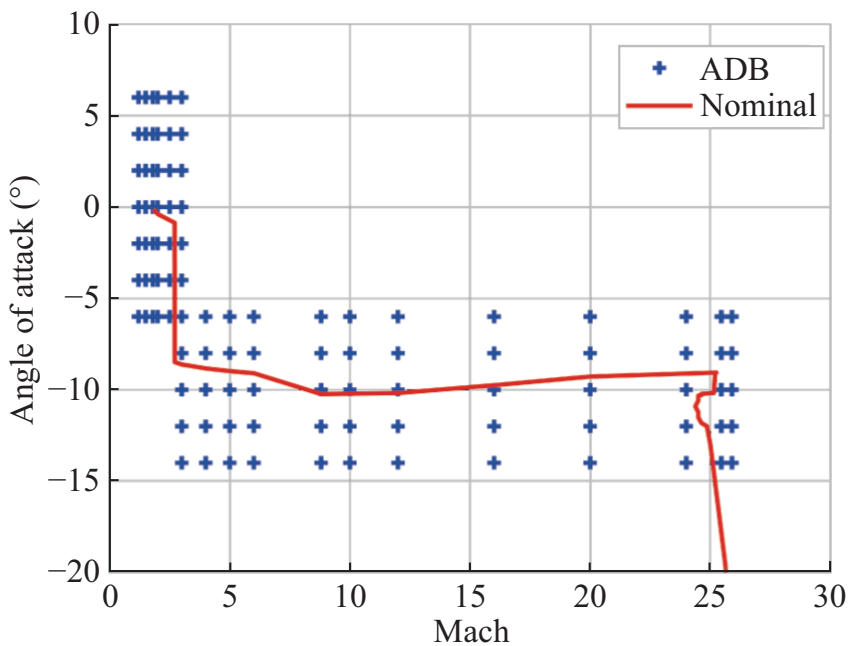

Fig. 4 Aerodynamic database.

\subsection{Aerodynamic state estimation}

The modeling of any physical phenomenon requires a dimensional analysis by identifying the independent variables. The generic aerodynamics of the entry process suggest that the aerodynamic state vector $\boldsymbol{X}$ has four independent variables [2].

$$
\boldsymbol{X}=\left[\begin{array}{c}
\alpha \\
\beta \\
p_{\mathrm{t}} \\
p_{\infty}
\end{array}\right]
$$

where $\alpha$ is the angle of attack, $\beta$ is the angle of sideslip, $p_{\mathrm{t}}$ is the total pressure, and $p_{\infty}$ is the static pressure.

However, the formulation of the aerodynamic state vector $\boldsymbol{X}$ is not unique. A combination of the angle of attack $\alpha$, the angle of sideslip $\beta$, and any two variables from the set of total pressure $p_{\mathrm{t}}$, static pressure $p_{\infty}$, dynamic pressure $\bar{q}$, pressure ratio $R$, and free stream Mach number $M_{\infty}$ is applicable. It is natural to select $p_{\mathrm{t}}$ and $p_{\infty}$ as the other two variables in addition to the wind-relative angles because the measured data are in the form of pressure as well.

The normal shock relation is applied to calculate the pressure ratio $R$ in the supersonic and subsonic regimes.

$$
\begin{aligned}
& R=\frac{p_{\infty}}{p_{\mathrm{t}}}= \\
& \begin{cases}{\left[\frac{2}{(\gamma+1) M_{\infty}^{2}}\right]^{\frac{\gamma}{\gamma-1}}\left[\frac{2 \gamma M_{\infty}^{2}-(\gamma-1)}{\gamma+1}\right]^{\frac{1}{\gamma-1}}, M_{\infty}>1} \\
\left(1+\frac{\gamma-1}{2} M_{\infty}^{2}\right)^{\frac{-\gamma}{\gamma-1}}, & M_{\infty} \leqslant 1\end{cases}
\end{aligned}
$$

where $p_{\infty}$ is the static pressure, $p_{\mathrm{t}}$ is the total pressure, $\gamma$ is the ratio of specific heats obtained from the $\mathrm{ADB}$, and $M_{\infty}$ is the free stream Mach number. The speed of sound is estimated using the IMU-derived velocity to compute the Mach number.

The dynamic pressure $\bar{q}$ is derived from $p_{\infty}$ and $M_{\infty}$ as

$$
\bar{q}=\frac{\gamma}{2} p_{\infty} M_{\infty}^{2}=\frac{\gamma}{2} p_{\mathrm{t}} R M_{\infty}^{2}
$$

The relationship between the measured pressure $\boldsymbol{P}$ and the state vector $\boldsymbol{X}$ can be represented as

$$
\boldsymbol{P}=\boldsymbol{f}(\boldsymbol{X})+\varepsilon
$$

where

$$
\boldsymbol{P}=\left[\begin{array}{c}
P_{1} \\
P_{2} \\
\vdots \\
P_{n}
\end{array}\right], \boldsymbol{f}=\left[\begin{array}{c}
f_{1}(\boldsymbol{X}) \\
f_{2}(\boldsymbol{X}) \\
\vdots \\
f_{n}(\boldsymbol{X})
\end{array}\right], \boldsymbol{\varepsilon}=\left[\begin{array}{c}
\varepsilon_{1} \\
\varepsilon_{2} \\
\vdots \\
\varepsilon_{n}
\end{array}\right]
$$

Here, $P_{i}(i=1, \cdots, n)$ is the measured pressure data corresponding to orifice $i, f_{i}(\boldsymbol{X})$ is the CFD-based pressure model, and $\varepsilon_{i}$ is the error in the observed pressure $p_{i}$, assumed to have zero mean. Linearization of the pressure model results in the following approximation to Eq. (4):

$$
\boldsymbol{P}=\boldsymbol{f}(\hat{\boldsymbol{X}})+\boldsymbol{H}(\boldsymbol{X}-\hat{\boldsymbol{X}})+\boldsymbol{\varepsilon}
$$

where $\hat{\boldsymbol{X}}$ is a reference state in Fig. 4 , and $\boldsymbol{H}$ is the Jacobian matrix: 


$$
\boldsymbol{H}=\left[\frac{\partial \boldsymbol{f}}{\partial \boldsymbol{X}}\right]_{\boldsymbol{X}=\hat{\boldsymbol{X}}}
$$

which is also known as the sensitivity matrix. Equation (4) can be rewritten in a linear regression form:

$$
\boldsymbol{y}=\boldsymbol{H}(\boldsymbol{X}-\hat{\boldsymbol{X}})+\varepsilon
$$

where the residual vector:

$$
\boldsymbol{y}=\boldsymbol{P}-\boldsymbol{f}(\hat{\boldsymbol{X}})
$$

Consequently, the best linear unbiased estimate of $\boldsymbol{X}$ is computed as [18]:

$$
\hat{\boldsymbol{X}}=\left(\boldsymbol{H}^{\mathrm{T}} \boldsymbol{S}^{-1} \boldsymbol{H}\right)^{-1} \boldsymbol{H}^{\mathrm{T}} \boldsymbol{S}^{-1} \boldsymbol{y}
$$

where $\boldsymbol{S}$ is the pressure measurement error covariance matrix.

\subsection{Atmosphere reconstruction}

The atmospheric parameters can be estimated using both FADS and IMU data. The static pressure is one of the four elements in the best estimate of $\boldsymbol{X}$. The atmospheric density is derived from $\bar{q}$ and $V_{\mathrm{t}}$ as follows:

$$
\rho_{\infty}=\frac{2 \bar{q}}{V_{\mathrm{t}}^{2}}
$$

The axial forces can be estimated using acceleration measurements from the IMU. The axial force coefficients $C_{\mathrm{A}}, C_{\mathrm{N}}$, and $C_{\mathrm{Z}}$ are computed as follows:

$$
\left\{\begin{array}{l}
C_{\mathrm{A}}=\frac{m a_{x}}{\bar{q} S} \\
C_{\mathrm{N}}=\frac{m a_{y}}{\bar{q} S} \\
C_{\mathrm{Z}}=\frac{m a_{z}}{\bar{q} S}
\end{array}\right.
$$

where $m$ is the vehicle mass, $a_{x}, a_{y}$, and $a_{z}$ are accelerations in each body axis, and $S$ is the aerodynamic reference area.

The drag and lift coefficients $C_{\mathrm{D}}$ and $C_{\mathrm{L}}$ are defined as

$$
\left\{\begin{array}{l}
C_{\mathrm{D}}=C_{\mathrm{N}} \sin \alpha+C_{\mathrm{A}} \cos \alpha \\
C_{\mathrm{L}}=C_{\mathrm{N}} \cos \alpha-C_{\mathrm{A}} \sin \alpha
\end{array}\right.
$$

The lift/drag ratio $L / D$ is given by

$$
L / D=C_{\mathrm{L}} / C_{\mathrm{D}}
$$

\section{Results}

\subsection{Trajectory}

The trajectory reconstruction of Tianwen-1 was completed mostly based on data acquired from the IMU, as shown in Fig. 5, where Fig. 5(a) shows the result of the estimated altitude versus velocity, and Figs. 5(b)-5(d) show the Mach number, altitude, and dynamic pressure, respectively. The blue dashed line refers to the result reconstructed solely from the IMU data, and the red solid line represents the result from the combined IMU and FADS data. Atmospheric entry was initiated at $125 \mathrm{~km}$, with an entry angle of $-11.53^{\circ}$. The vehicle bears a peak pressure $134 \mathrm{~s}$ after entry. The differences in Mach number existing at high altitudes between the results reconstructed from the combined IMU and FADS data and that from the IMU data in Fig. 5(b) result from the low pressure of the rarefied Martian atmosphere, which cannot be distinguished by onboard pressure sensors.

\subsection{Wind-relative attitude}

The wind-relative attitude estimates are shown in Figs. 6(a) and 6(b). The wind-relative angles of attack and sideslip are compared with the planet-relative angles, design nominal value, and minimum and maximum design boundaries. The minimum, maximum, and nominal values were derived from the trim angles of attack. The nominal value of the angle of sideslip is basically zero. The control system constantly corrects the angle of sideslip toward zero within an acceptable range of $\pm 4^{\circ}$. The wind-relative and planet-relative angles match fairly well during hypersonic flight, as expected, because the magnitudes of the total velocity of the vehicle are much greater than the wind. The angles become more sensitive to wind as the vehicle decelerates, especially near the end of the trajectory.

The difference between the FADS and IMU results at low Mach numbers indicates the suspected winds, which are discussed in the following sections. The trim tab was triggered on at 2.71 Mach (in flight, 2.8 Mach nominal), approximately $250 \mathrm{~s}$ after entry, to level the angle of attack toward zero for succeeding parachute deployment. The corresponding jump in the angle of attack and sideslip was caused by this trim tab deployment.

\subsection{Atmosphere}

The combined envelope of two Martian atmosphere models was applied as the design reference [28, 29]. A comparison between the reconstructed atmospheric environment and the design envelope is shown in Fig. 7. The minimum, maximum, and nominal values are computed from the atmosphere models on the date of entry. The atmospheric density reaches the design upper bound at altitudes below $15 \mathrm{~km}$. This deviation between 


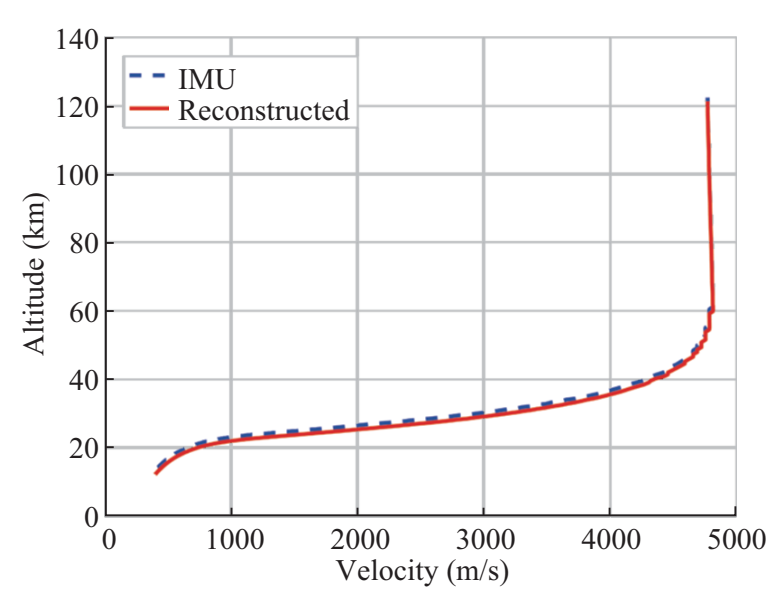

(a) Altitude vs. velocity

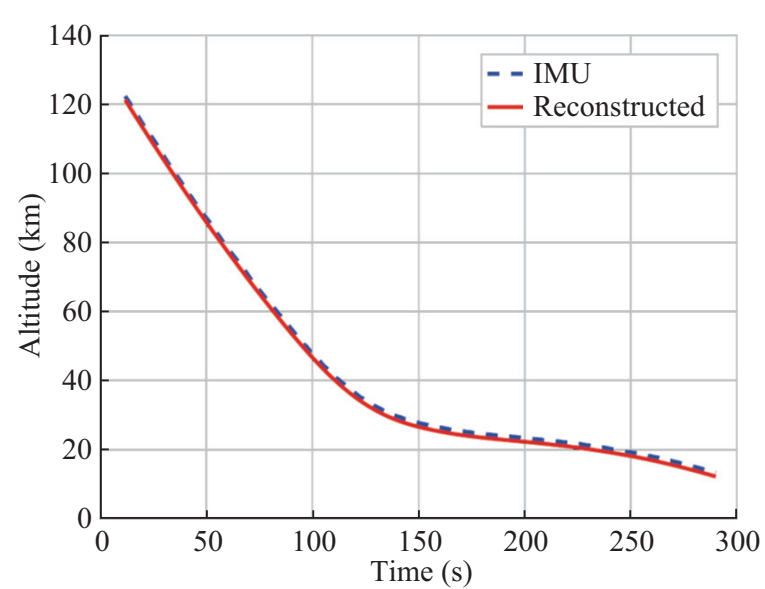

(c) Altitude

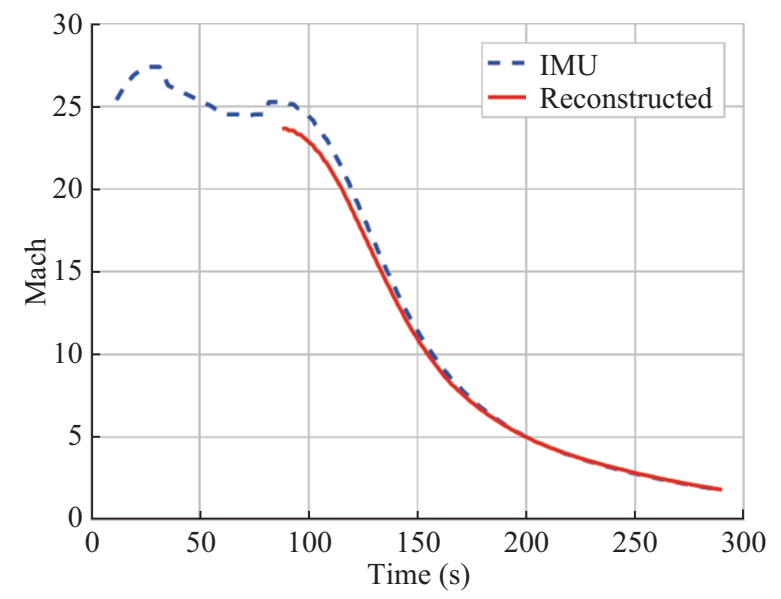

(b) Mach

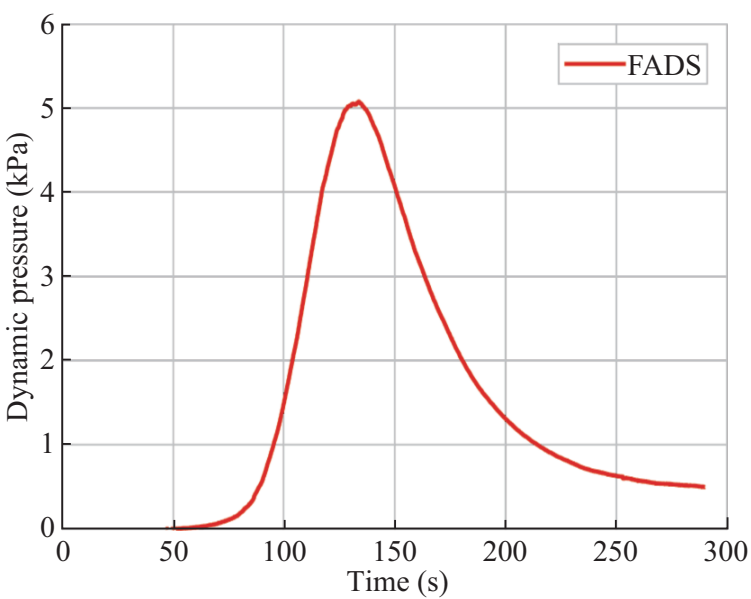

(d) Dynamic pressure

Fig. 5 Reconstructed trajectory.

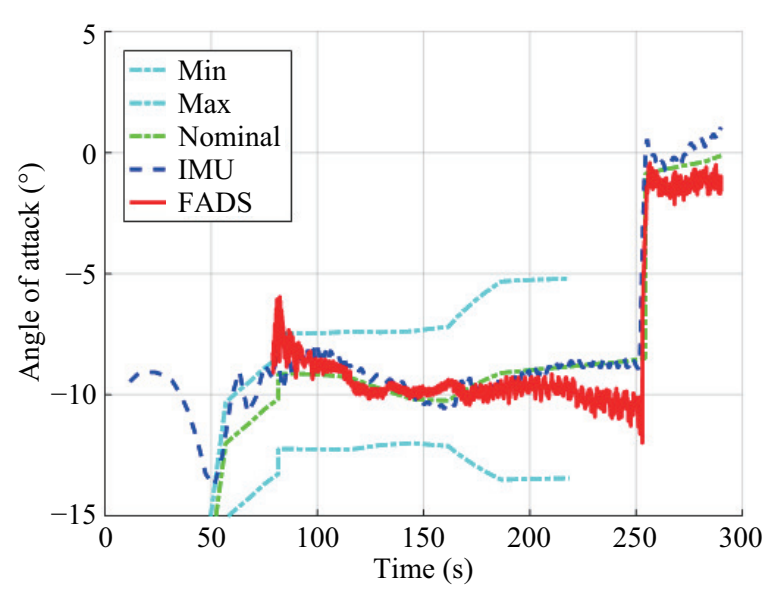

(a) Angle of attack

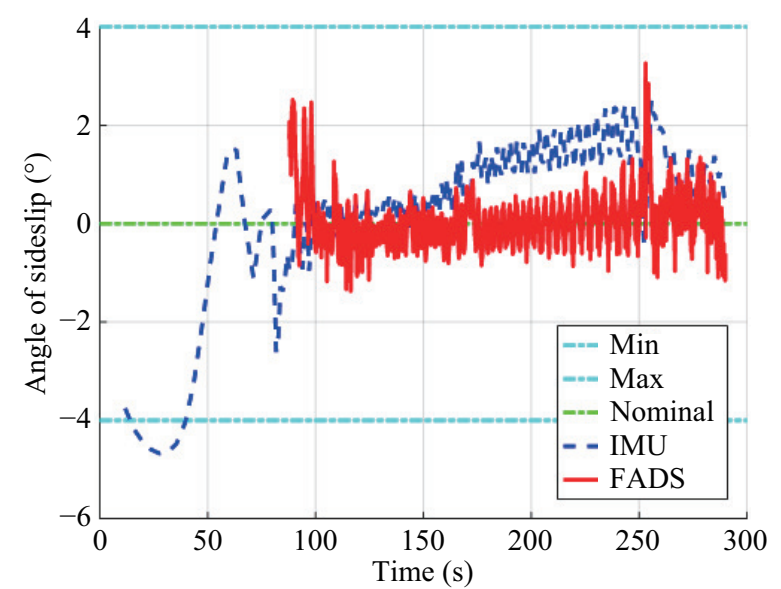

(b) Angle of sideslip

Fig. 6 Wind-relative attitude estimates. 
the flight result and the design nominal value may come from the choice of model parameters regarding entry interface, solar activity, season, optical depth, etc.

Wind components can be extracted by recomposing the wind-relative velocity into planet-relative coordinate systems. The differences between the reconstructed velocities from the IMU and the combined IMU and FADS results represent the wind components. The estimates of the local wind components in the north-east-down frame are shown in Fig. 8. The minimum and maximum values are the envelopes of the results of the two atmosphere models. The flight results fall within the design boundary. The results suggest that both a north wind component and a west wind component exist, indicating a constant northwest wind field below $50 \mathrm{~km}$. An exception is at approximately $25 \mathrm{~km}$, where an east wind shear exists, as shown in Fig. 8(b). These nonzero wind components contribute to the deviation of the angle of attack and sideslip from the nominal design value.

\subsection{Aerodynamics}

The reconstructed aerodynamic force coefficients are shown in Fig. 9. The reconstructed coefficients are compared with the corresponding design values (the nominal dashed line) and the deviation band (the minimum and maximum dash-dot lines). Not until 130

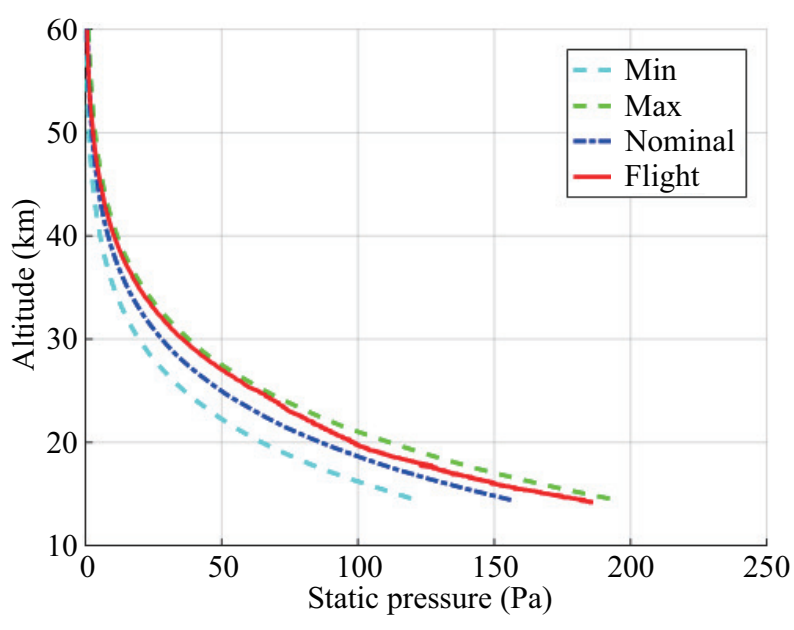

(a) Static pressure

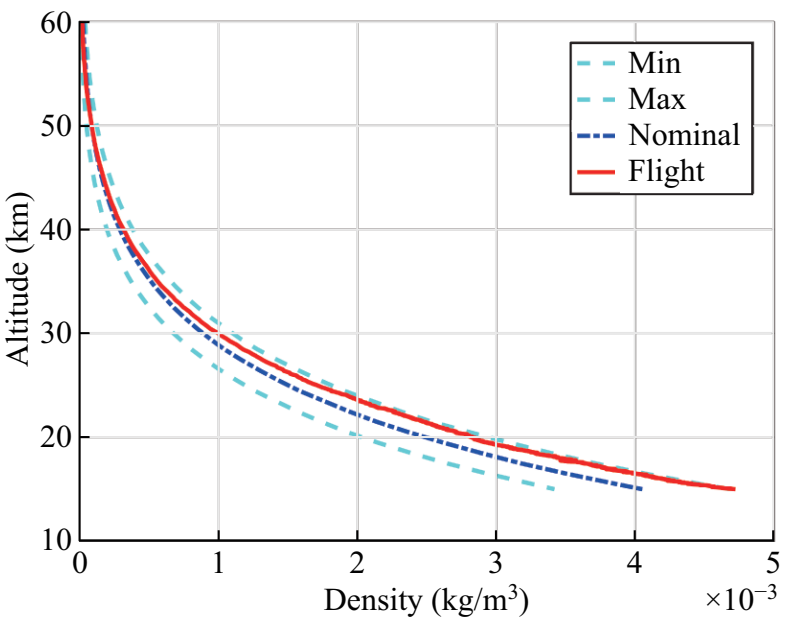

(b) Atmospheric density

Fig. 7 Atmosphere estimates.

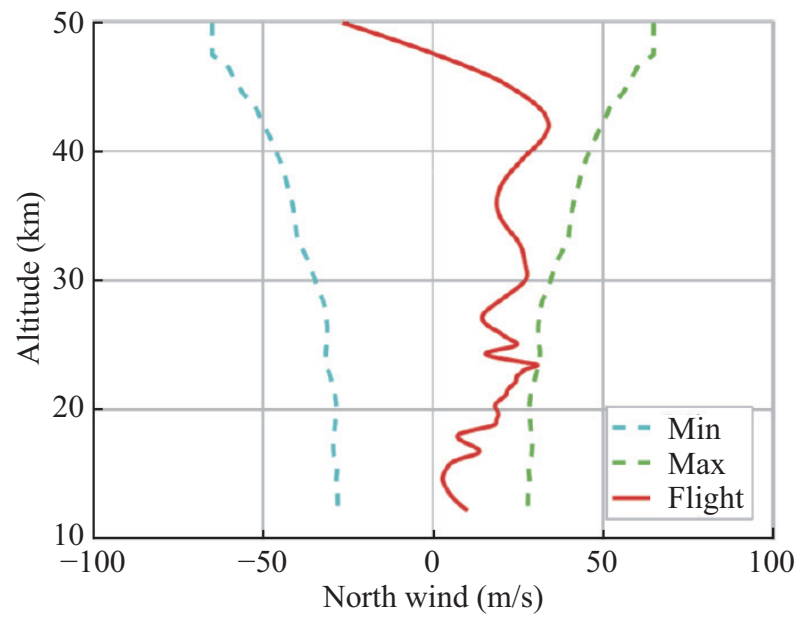

(a) North wind component

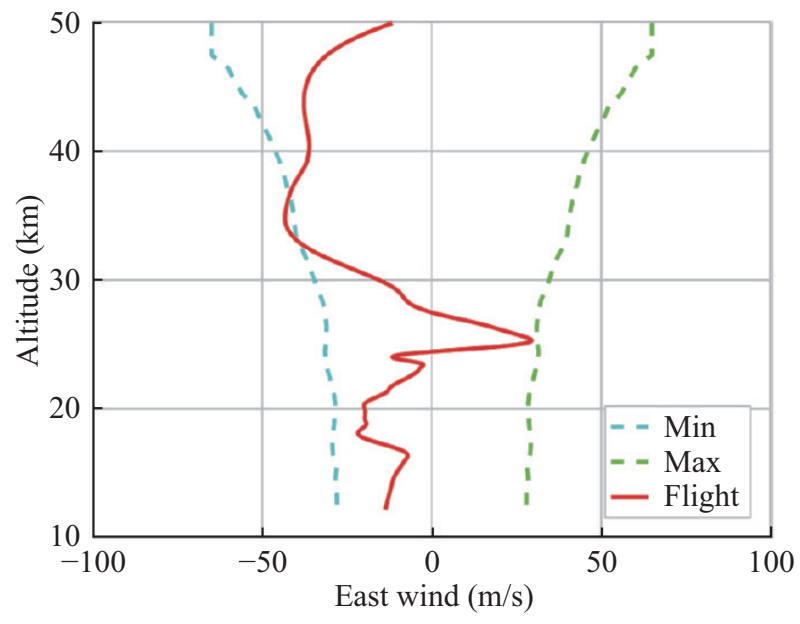

(b) East wind component

Fig. 8 Wind estimates. 


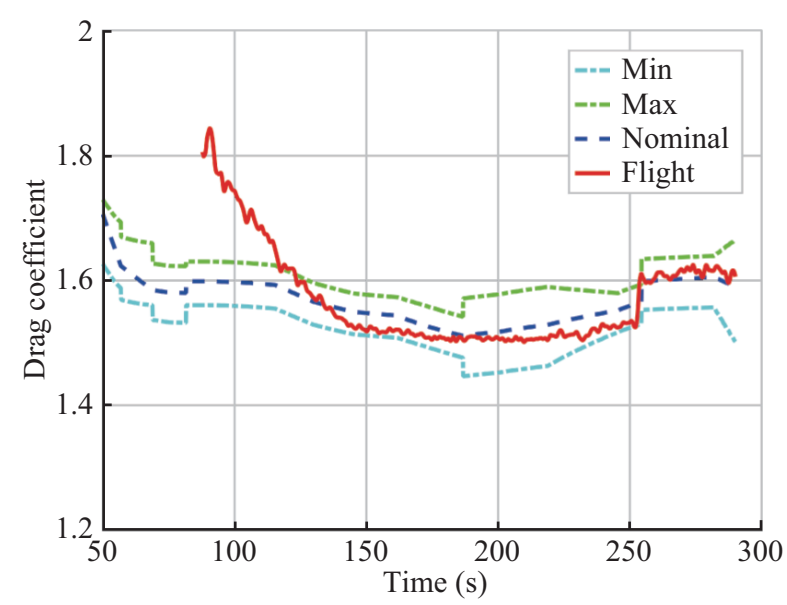

(a) Drag coefficient

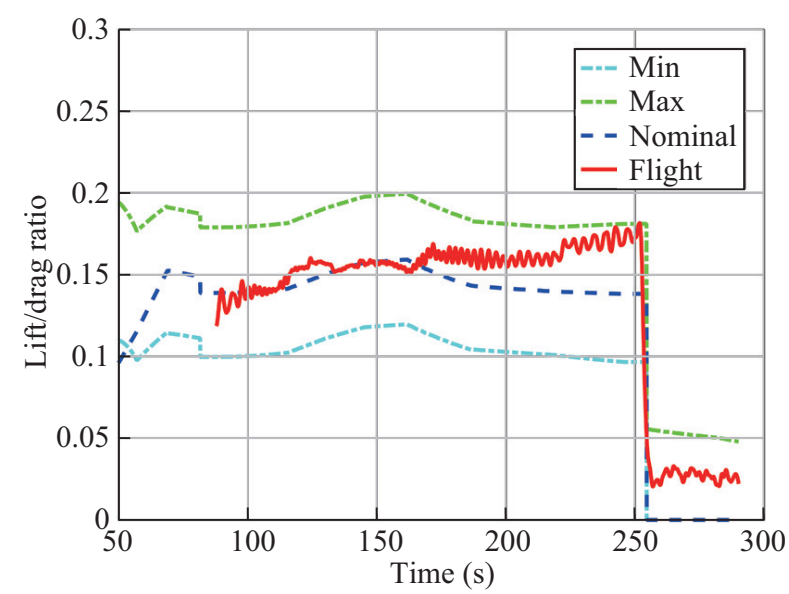

(c) Lift/drag ratio

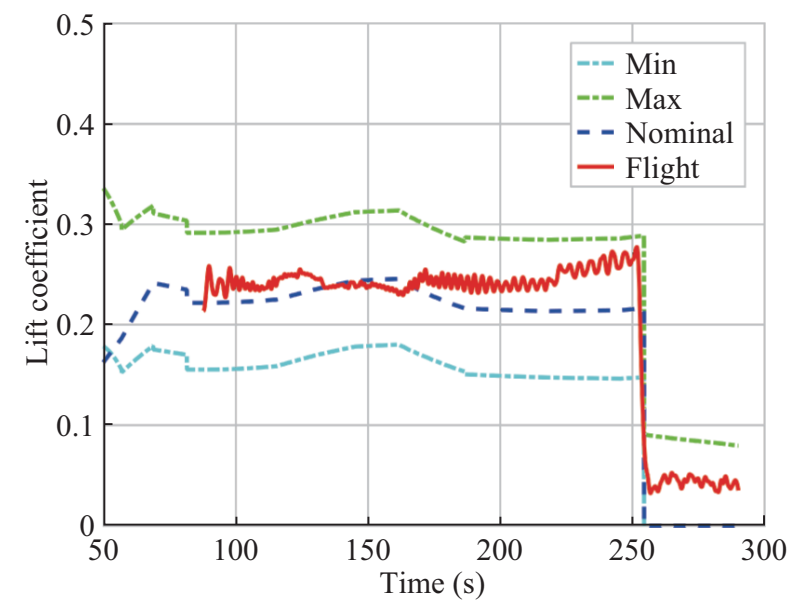

(b) Lift coefficient

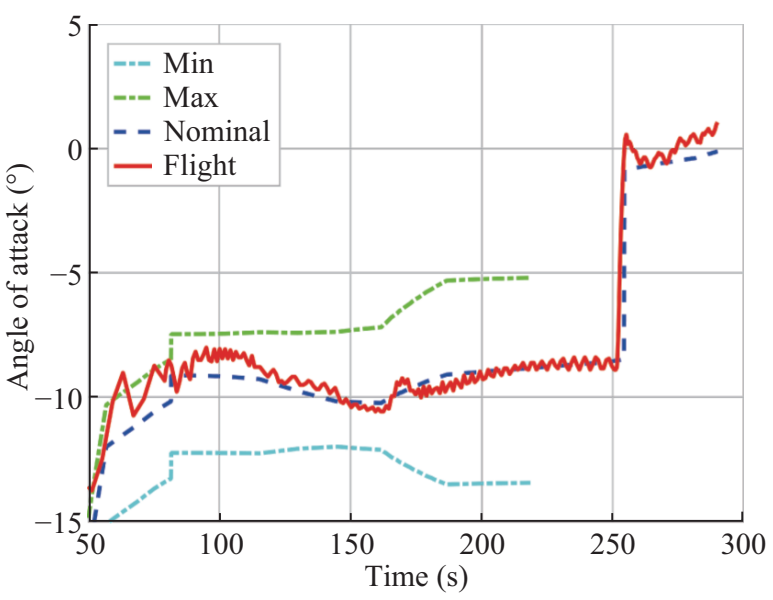

(d) Trim angle of attack

Fig. 9 Atmosphere estimates.

s after entry did the drag coefficient coincide with the design nominal value. The reason for this offset is that the aerodynamic force is negligible compared with the resolution of the acceleration measurements at high altitudes. The drag coefficient is only 0.02 smaller than the nominal value at most in the hypersonic and supersonic regimes, which is considered to agree fairly well. This difference was probably caused by the deviation of the atmosphere on the day of entry. A less likely but possible explanation is that the real gas effect differs from the design nominal value in features, including but not limited to the chemical reaction model and surface catalysis effect. The drag coefficient is in close agreement after the deployment of the trim tab in 2.8 Mach through 1.8. Furthermore, the lift coefficient agrees well with the design nominal value in all regimes, except for supersonic flight. The deviation between the reconstructed results and the nominal value increases as the vehicle descends. This deviation is most likely caused by the local wind (as stated in Section 4.3), which is no longer negligible below $25 \mathrm{~km}$. Consequently, the lift and drag ratio reaches the upper bound of the design value during supersonic flight. The trim angle of attack matches the design nominal value extremely well, indicating that the aerodynamic database is accurate and the control system works effectively.

\section{Conclusions}

A filter method for the trajectory reconstruction of the Tianwen-1 Mars entry vehicle was presented. The ADB was generated by the CFD method and covers the entire flight envelope. This is the foundation of the 
trajectory and atmosphere reconstruction. A combined reconstruction approach using data from both the IMU and the FADS is proposed. The wind-relative angles, atmospheric parameters, and wind components were estimated using this approach. The in situ atmospheric parameters, such as density and wind, were revealed by accurate dynamic pressure estimates obtained using the FADS. The aerodynamic force coefficients were estimated and compared with the design nominal values. The experience of Tianwen-1 should benefit future planetary EDL performances.

\section{Acknowledgements}

The authors are grateful to Ying Li for extraction of the raw pressure and temperature data, Fajun Yi for calibration of pressure sensors, Minwen Guo for providing inertial data, and Francois Forget and Millour Ehouarn for collaboration in the Martian atmospheric model.

\section{Conflict of interest}

The authors declare that there is no conflict of interest.

\section{References}

[1] Cury. J. P., Keener, E. R. Flight evaluation of the X-15 ball-nose flow-direction sensor as an air-data system. NASA TN D-2923, 1965.

[2] Pruett, C. D., Wolf, H., Heck, M. L., Siemers, P. M. Innovative air data system for the Space Shuttle Orbiter. Journal of Spacecraft and Rockets, 1983, 20(1): 61-69.

[3] While, D. M. Shuttle Entry Air Data System (SEADS) hardware development Volume II, history. NASA CR-166044, 1983.

[4] Siemers, P. M., Wolf, H., Flanagan, P. F. Shuttle Entry Air Data System concepts applied to Space Shuttle Orbiter flight pressure data to determine air data-STS 1-4. In: Proceedings of the 21st Aerospace Sciences Meeting, 1983: AIAA-83-0118.

[5] Whitmore, S., Cobleigh, B., Edward Haering, J. Design and calibration of the X-33 Flush Airdata Sensing (FADS) system. In: Proceedings of the 36th AIAA Aerospace Sciences Meeting and Exhibit, 1998.

[6] Cobleigh, B., Whitmore, S., Edward Haering, J., Borrer, J., Roback, V. Flush airdata sensing (FADS) system calibration procedures and results for blunt forebodies. In: Proceedings of the 9th International Space Planes and Hypersonic Systems and Technologies Conference, 1999: AIAA 99-4816.

[7] Chen, G. Q., Liu, W. Y., Dou, X. X., Zhou, W. J., Dou, G. H. Flushing air data sensing system design for air breathing air-to air missile. SCIENTIA SINICA Technologica, 2016, 46(11): 1193-1206. (in Chinese)

[8] Chen, G. Q., Wang, G. D., Chen, B. Y., Zhou, W. J., Ji, C. Q., Luo, X. Y. The study of flushing air data sensing technology for low cost flight test platform. Journal of Astronautics, 2015, 36(10): 1195-1202. (in Chinese)

[9] Ingoldby, R. N., Michel, F. C., Flaherty, T. M., Doty, M. G., Steele, R. D. Entry data analysis for Viking landers 1 and 2. NASA TN-3770218, NASA CR-159388, 1976.

[10] Euler, E. A., Adams, G. L., Hopper, F. W. Design and reconstruction of the Viking lander descent trajectories. Journal of Guidance and Control, 1978, 1(5): 372-378.

[11] Spencer, D. A., Blanchard, R. C., Braun, R. D., Kallemeyn, P. H., Thurman, S. W. Mars Pathfinder entry, descent, and landing reconstruction. Journal of Spacecraft and Rockets, 1999, 36(3): 357-366.

[12] Withers, P., Towner, M. C., Hathi, B., Zarnecki, J. C. Analysis of entry accelerometer data: A case study of Mars Pathfinder. Planetary and Space Science, 2003, 51(9-10): 541-561.

[13] Withers, P., Smith, M. D. Atmospheric entry profiles from the Mars exploration rovers spirit and opportunity. Icarus, 2006, 185(1): 133-142.

[14] Desai, P. N., Blanchard, R. C., Powell, R. W. Entry trajectory and atmosphere reconstruction methodologies for the Mars Exploration Rover mission. In: Proceedings of the International Workshop on Planetary Probe Atmospheric Entry and Descent Trajectory Analysis and Science, 2004: 20040031558.

[15] Blanchard, R. C., Desai, P. N. Mars phoenix entry, descent, and landing trajestory and atmosphere reconstruction. Journal of Spacecraft and Rockets, 2011, 48(5): 809-822.

[16] Gazarik, M. J., Wright, M. J., Little, A., Cheatwood, F. M., Herath, J. A., Munk, M. M., Novak, F. J., Martinez, E. R. Overview of the MEDLI project. In: Proceedings of the IEEE Aerospace Conference, 2008: 1-12.

[17] Cheatwood, F. M., Bose, D., Karlgaard, C. D., Kuhl, C. A., Santos, J. A., Wright, M. J. Mars Science Laboratory (MSL) entry, descent, and landing instrumentation (MEDLI): Complete flight data set. NASA/TM 2014-218533, 2014.

[18] Karlgaard, C. D., Kutty, P., Schoenenberger, M., Munk, M. M., Little, A., Kuhl, C. A., Shidner, J. Mars science laboratory entry atmospheric data system trajectory and atmosphere reconstruction. Journal of Spacecraft and Rockets, 2014, 51(4): 1029-1047.

[19] Kutty, P., Karlgaard, C. D. Mars science laboratory aerodatabase trajectory reconstruction and uncertainty assessment. In: Proceedings of the AIAA Atmospheric Flight Mechanics Conference, 2014: AIAA 2014-1094. 
[20] Schoenenberger, M., van Norman, J., Karlgaard, C., Kutty, P., Way, D. Assessment of the reconstructed aerodynamics of the Mars Science Laboratory entry vehicle. Jounral of Spacecraft and Rockets, 2014, 51(4): 1076-1093.

[21] Little, A., Bose, D., Karlgaard, C. D., Munk, M., Kuhl, C., Schoenenberger, M., Antill, C., Verhappen, R., Kutty, P., White, T. The Mars Science Laboratory (MSL) Entry, Descent and Landing Instrumentation (MEDLI): Hardware performance and data reconstruction. In: Proceedings of the 36th AAS Guidance and Control Conference, 2013: AAS 13-078.

[22] Karlgaard, C. D., Kutty, P., Schoenenberger, M., Shidner, J. D. Mars Science Laboratory entry, descent, and landing trajectory and atmosphere reconstruction. In: Proceedings of the 23rd AAS/AIAA Space Flight Mechanics, 2013: AAS 13-307.

[23] Karlgaard, C., Kutty, P., Shidner, J., Schoenenberger, M., Munk, M. Mars entry atmospheric data system trajectory reconstruction algorithms and flight results. In: Proceedings of the 51st AIAA Aerospace Sciences Meeting including the New Horizons Forum and Aerospace Exposition, 2013: AIAA 2013-0028.

[24] Karlgaard, C. D., van Norman, J., Siemers, III, P. M., Schoenenberger, M., Munk, M. M. Mars Entry Atmospheric data system modeling, calibration, and error analysis. NASA TM-2014-218535, 2014.

[25] Karlgaard, C. D., Beck, R. E., O'Keefe, S. A., Siemers, III, P. M., White, T., Engelund, W. C., Munk, M. M. Mars entry atmospheric data system modelling and algorithm development. In: Proceedings of the 41st AIAA Thermophysics Conference, 2009: AIAA 2009-3916.

[26] White, T. R., Mahzari, M., Tang, C., Schoenenberger, M., Cruden, B. A. The entry descent and landing instrumentation (MEDLI2) suite for the Mars 2020 mission. In: Proceedings of the 16th International Planetary Probe Workshop, 2019.

[27] Hwang, H., Bose, D., Wright, H., White, T. R., Schoenenberger, M., Santos, J., Karlgaard, C. D., Kuhl, C., Oishi, T., Trombetta, D. Mars 2020 entry, descent, and landing instrumentation (MEDLI2). In: Proceedings of the 46th AIAA Thermophysics Conference, 2016: 2016-3536.

[28] Vaughan, R. Mars Pathfinder project: Planetary constants and models. Report No. JPL D-12947. U.S. Jet Propulsion Laboratory, California Institute of Technology, 1995.

[29] Bresciani, F. ExoMars 2018 flight and Mars surface space environment requirements specification. EXM-M2SSR-A1-0029, 2013.

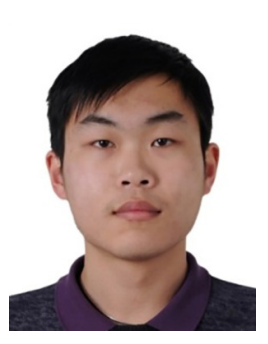

Haogong Wei is a systems engineer at Beijing Institute of Spacecraft System Engineering, working in the area of planetary entry, descent, and landing. He is the recipient of the second prize of Science and Technology Progress Award of China Aerospace Science and Technology Corporation. He received his B.S. degree in aerospace engineering from Beijing Institute of Technology, and his M.S. degree in aeronautical and astronautical engineering from Purdue University. E-mail: weihaogong@aliyun.com.

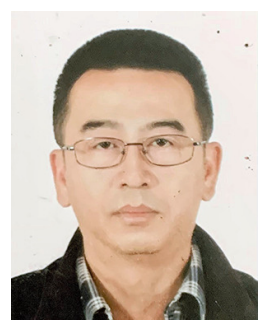

Wei Rao, researcher, was graduated from Beihang University in August 1993. He participated in the development of Chang'e-1, Chang'e-2 lunar probes and Mars probes, serving as the product assurance manager and deputy designer of Mars probes. He has won the third prize of National Defense Science and Technology Progress Award once, the special prize of National Science and Technology Progress Award twice, the National Outstanding Youth, etc.

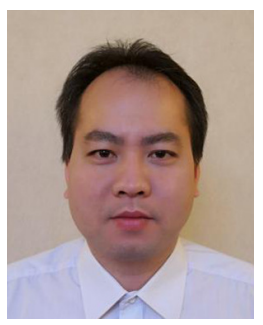

Guangqiang Chen, senior engineer of China Academy of Aerodynamics of Aerospace (CAAA), was graduated from Beihang University in January 2008. He is academically focusing on flushing air data sensing (FADS) technologies, including algorithmic design method based on neural network technology, fault diagnosis and fault tolerance design, wind tunnel test calibration, etc. E-mail: guangqiangchen@sina.com.

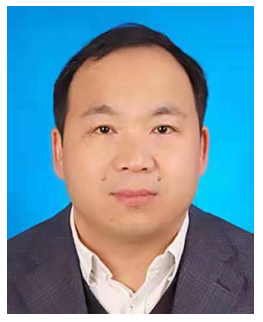

Guidong Wang, researcher, Ph.D. in fluid mechanics, was graduated from Northwestern Polytechnical University in August 1998. He completed the aerodynamic identification research of dozens of flight test of Shenzhou spacecraft, lunar spacecraft, and other aircraft. He has won the first prize of Science and Technology Progress of Sichuan Province and the third prize of Science and Technology Progress of China Aerospace Science and Technology Corporation. 


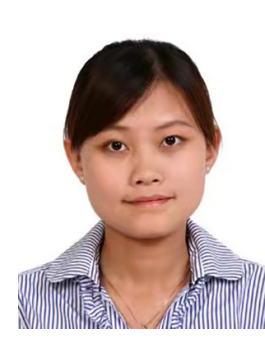

Xin Zou, senior engineer, was graduated from Changchun University of Science and Technology in 2009. As the chief designer of the engineer parameter measurement system, she is responsible for the measurement system design, analysis, and verification of Chang'e- 5 and Mars probes. She has won the third prize of Science and Technology Progress of Beijing Municipality.

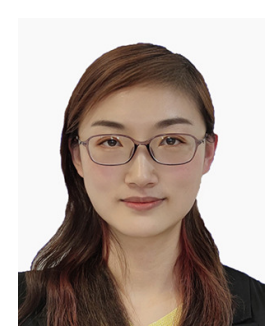

Qi Li, researcher, was graduated from Beihang University in 2008 with a degree in fluid mechanics. As the head of the Entry and Re-entry Pneumatic Department, she is responsible for the aerodynamic design, analysis, and verification of Chang'e-5 and Mars probes. She has won the first prize of Science and Technology Progress łof Sichuan Province and the second prize of Science and Technology Progress Award of China Aerospace Science and Technology Corporation.

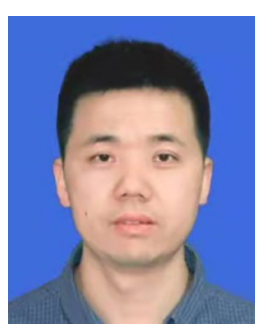

Yanqi Hu received his Ph.D. degree in space physics from National Space Science Center in 2008. Since 2008, he has been an engineer with the Beijing Institute of Spacecraft System Engineering, China Academy of Space Technology, Beijing. His current research interests include radiation effect simulation of spacecraft, space environment modeling, and Mars atmosphere.
Open Access This article is licensed under a Creative Commons Attribution 4.0 International License, which permits use, sharing, adaptation, distribution and reproduction in any medium or format, as long as you give appropriate credit to the original author(s) and the source, provide a link to the Creative Commons licence, and indicate if changes were made.

The images or other third party material in this article are included in the article's Creative Commons licence, unless indicated otherwise in a credit line to the material. If material is not included in the article's Creative Commons licence and your intended use is not permitted by statutory regulation or exceeds the permitted use, you will need to obtain permission directly from the copyright holder.

To view a copy of this licence, visit http://creativecomm ons.org/licenses/by/4.0/. 